\title{
Severe metabolic acidosis and respiratory distress due to acute starvation in pregnancy: a case report
}

\begin{abstract}
Maternal acidosis, due to acute starvation, is a medical emergency in which both mother and child are at risk for significant morbidity and mortality. Acute starvation in the third trimester of pregnancy causing maternal ketoacidosis should be identified rapidly, followed by the right treatment immediately. If starvation has occurred, substituting nutrients, intravenous glucose and prevention of circulatory hypovolemia are recommended. This case report presents a pregnant woman with acute starvation ketoacidosis. In this case, we present warning symptoms, such as respiratory distress, and the severe consequences of maternal acidosis.
\end{abstract}

Volume II Issue 6 - 2020

\author{
Kelly de Jong,' Carissah JC Stewart, ${ }^{2}$ Gretel \\ CR van Hoecke,' Huibert H Ponssen ${ }^{2}$ \\ 'Department of Obstetrics and Gynecology, Albert Schweitzer \\ Hospital, Dordrecht, the Netherlands \\ ${ }^{2}$ Department of Intensive Care, Albert Schweitzer Hospital, \\ Dordrecht, the Netherlands
}

Correspondence: Kelly de Jong, Albert Schweitzer Hospital,
Albert Schweitzerplaats 25, 33।8 AT Dordrecht, The Netherlands, Tel 003I-7865-51948, Email k.dejong2@asz.nl

Received: November 02, 2020 | Published: November 10, 2020

\section{Introduction}

Acute starvation ketoacidosis in pregnancy is a rare condition with a severe course of disease for both mother and unborn child. Early recognition and immediate management are required to minimize the risk of severe outcomes. Patients with diabetes mellitus type 1 or alcohol abusis are more at risk at ketoacidosis. ${ }^{1,2}$ In rare cases, metabolic acidosis can be a consequence of acute starvation in the third trimester of pregnancy in non-diabetic patients. ${ }^{3-8}$

Many cases show patients presenting themselves with a short period of fasting, accompanied by vomiting while patients look clinically well. ${ }^{5}$ This kind of presentation also may cause a delay in recognition and therapy, resulting in a progression of metabolic acidosis with potentially fatal consequences. We describe a case of respiratory distress and starvation-induced severe metabolic acidosis during the third trimester in a pregnancy complicated by preeclampsia and gestational diabetes.

\section{Case}

A 29-year-old multipara woman, at 28 weeks of gestation, presented with dyspnoea, maternal tachycardia and tachypnea. Past medical history included an appendectomy and one uncomplicated previous pregnancy. At the first presentation, a CT-scan was performed, which showed no signs of lung embolism.

At a gestation of 30 weeks, pregnancy-induced hypertension was diagnosed with a blood pressure of $140 / 80 \mathrm{mmHg}$. There were no abnormalities in laboratory results urinalysis and cardiotocograph. After one week, at a gestation of 31 weeks and 2 days, blood pressure raised to $150 / 84 \mathrm{mmHg}$, after which methyldopa $500 \mathrm{mg} 3$ times a day was started. Fasting glucose was $7.7 \mathrm{mmol} / \mathrm{L}$ (normal range: $<7.0 \mathrm{mmol} / \mathrm{L}$ ) and the diagnosis of gestational diabetes was diagnozed, wherefor dietary advice was given and no antidiabetic medication was started.

At 34 weeks of gestation, the patient presented malaise and false contractions. Urinalysis showed $2+$ protein with a protein-creatinine ratio of $92.1 \mathrm{mg} / \mathrm{mmol}$ (normal $<30 \mathrm{mg} / \mathrm{mmol}$ ). The complains of malaise were accompanied by dyspnoea and palpitations. Physical examination showed a maternal tachycardia of $124 \mathrm{bpm}$, a respiratory rate of 24 breaths per minute and blood pressure of $130 / 75 \mathrm{mmHg}$. Due to the presence of hypertension and albuminuria, preeclampsia was diagnosed. Another CT-scan was performed, which again showed no signs of pulmonary embolism. Random glucose was $9.6 \mathrm{mmol} / \mathrm{L}$ without antidiabetic medication. Laboratory results showed a hypokalaemia of $3.3 \mathrm{mmol} / \mathrm{L}$ (normal $3.5-5.0 \mathrm{mmol} / \mathrm{L}$ ) without other abnormalities. The patient was admitted at the obstetric unit for observation and further analysis, with preeclampsia.

The next day $(34+1)$, the symptoms persisted and were accompanied by nausea. A physical examination showed a blood pressure of $135 / 69 \mathrm{mmHg}$, a heart rate of $110 \mathrm{bpm}$ and a saturation of $99 \%$. There was no registration of the respiratory rate. There were no signs of oedema, and the knee reflexes were normal. A systolic souffle was found during auscultation. Cardiologic exam indicated hyperdynamic circulation and anaemia (haemoglobin: $7.7 \mathrm{mmol} / \mathrm{L}$ ).

At a gestation of 34 weeks and 2 days, symptoms were unchanged. Due to high fasting glucose $(7.2 \mathrm{mmol} / \mathrm{L})$, treatment with insulin was started. Due to gestational diabetes, an ultrasound examination was performed: head circumference (HC) p98, abdominal circumference $(\mathrm{AC})>\mathrm{p} 100$ and estimated fetal weight $(\mathrm{EFW})>\mathrm{p} 100$, from which macrosomia was concluded. Laboratory results still showed a hypokalaemia of $3.4 \mathrm{mmol} / \mathrm{L}$, as well as an elevated uric acid of $0.57 \mathrm{mmol} / \mathrm{L}(0.12-0.34 \mathrm{mmol} / \mathrm{L})$. 24-hour urine showed 0.66 grams of protein $(<0.30 \mathrm{gr} / 24 \mathrm{~h})$.

At a gestation of 34 weeks and 4 days, symptoms worsened with vomiting (three times a day) and increase of malaise. Respiratory rate was 24 breaths per minute, saturation $99 \%$ without oxygen, blood pressure $140 / 90 \mathrm{mmHg}$ and heart rate $120 \mathrm{bpm}$. During the physical exam, no other abnormalities were found. Due to high blood pressure, methyldopa was increased to $1000 \mathrm{mg}$ three times daily. Urinalysis showed $4+$ ketones. The blood test showed an elevated uric acid of 0.77 and random glucose of $6.8 \mathrm{mmol} / \mathrm{L}$. Rehydration with sodium chloride $0.9 \%$ was started. The insulin dosage was increased.

Three days later, the patient and her family expressed their concerns. Her blood pressure was $140 / 80 \mathrm{mmHg}$, maternal heart rate was $128 \mathrm{bpm}$, and her respiratory rate was $20-25$ per minute. 
The venous blood test showed a severe metabolic acidosis with an incomplete respiratory compensation $\left(\mathrm{pH} 7.15, \mathrm{pCO}_{2} 2.8 \mathrm{kPa}\right.$, bicarbonate $7.4 \mathrm{mmol} / \mathrm{L}$, base excess $-19.5 \mathrm{mmol} / \mathrm{L}$, Lactate 1.9 ) with an increased anion gap $(22.6 \mathrm{mmol} / \mathrm{L})$, for which the Intensive Care Unit (ICU) was consulted. The probability diagnosis was starvationinduced severe metabolic acidosis. The patient was given sodium bicarbonate $(8.4 \%)$, glucose and thiamine intravenously to correct the starvation acidosis.

Due to the severe acidosis, an emergency caesarean was performed under general anaesthesia, with a total blood loss of $800 \mathrm{cc}$. Perioperatively, the patient received $10 \%$ glucose IV $(2 \mathrm{~L} / 24 \mathrm{~h})$ to continu correcting the starvation. A male newborn (3850grams) was delivered with an APGAR score of 2/5/7 and a $\mathrm{pH}$ level of 7.05 , pCO2 $7.3 \mathrm{kPa}$, base excess $-14.9 \mathrm{mmol} / \mathrm{L}$. Her child was transferred to an academic centre for continuous positive airway pressure (CPAP) treatment due to idiopathic respiratory distress syndrome (IRDS) and hypoglycaemia. On arrival at ICU, the patient had a blood pressure of $151 / 94 \mathrm{mmHg}$, a pulse of 140/min and patient was still intubated. Admission arterial blood gas showed a persisting severe metabolic acidosis $(\mathrm{pH} 7.14$, $\mathrm{pCO}_{2} 4.1 \mathrm{kPa}$, base excess $-17.2 \mathrm{mmol} / \mathrm{L}$, bicarbonate $10.5 \mathrm{mmol} / \mathrm{L}$ ) Further laboratory findings showed an anion gap $21 \mathrm{mmol} / \mathrm{L}$, chloride $111.0 \mathrm{mmol} / \mathrm{L}$, lactate $1.9 \mathrm{mmol} / \mathrm{L}$ and a glucose $22.5 \mathrm{mmol} / \mathrm{L}$.

The intravenous glucose (10\%) fluid, alongside a sodium chloride fluid therapy, was continued. Furthermore, intravenous insulin, potassium and thiamine were started, to compensate for the electrolyte shift induced by the therapy.

The patient was quickly and successfully extubated. The acid-base balance returned to normal within 24 hours of the ICU admission. The ketonuria disappeared within 48 hours of treatment. The patient was then discharged to the department of obstetrics.

\section{Discussion}

Our patient represents the severe consequenses of acute starvation causing significant acid-base disturbances. Signals of acidosis such as the respiratory distress (dyspnoea and tachypnea) did already occur at a gestation of 34 weeks. When starvation ketoacidosis was diagnosed, the laboratory results revealed a severe metabolic acidosis with a high anion gap $(22.6 \mathrm{mmol} / \mathrm{L})$. The anion gap is used to distinguish the aetiology of the metabolic acidosis. Causes of a high anion gap are the presence of high lactate, ketones or exogenous acids. Our patient did not have elevated lactate $(1.9 \mathrm{mmol} / \mathrm{L})$ or signs of been exposed to any exogenous acids during pregnancy, but there were elevated amounts of ketones present in her urine sample, which affirmed our diagnosis of starvation ketoacidosis.

Causes of ketoacidosis within pregnancy are alcohol-induced, uncontrolled diabetes, or starvation-induced. ${ }^{5}$ The lack of elevated lactate, alcohol abuse and hyperglycemia (glucose $>13.9 \mathrm{mmol} / \mathrm{L})^{9}$ made us to exclude lactate acidosis, alcohol-induced acidosis and diabetic ketoacidosis. As seen in other cases, the most likely diagnosis was starvation ketoacidosis due to the acute starvation that our patient endured prior to the worsening of her symptoms. ${ }^{6,8}$ Furthermore, the metabolic disturbance in our case was rapidly corrected by substituting nutrients with intravenous glucose fluids, insulin, sodium bicarbonate, potassium and thiamine, which confirmed our diagnosis as seen in other cases ${ }^{3}$

Pregnant women have more risks to develop starvation ketoacidosis compared to non-pregnant women. ${ }^{5}$ In healthy nonpregnant women, it takes up to 14 days to reach the maximum of the severity of starvation ketoacidosis, which would manifest with mildly elevated ketoacid levels and minimal acid-base disturbances. ${ }^{5}$ Earlier research has shown that starvation ketoacidosis can be present in pregnant women in such an accelerated state, that it might manifest, even within 12-14 hours. ${ }^{5}$ This accelerated development is due to many factors including insulin resistance, increased lipolysis and ketogenesis that occur during pregnancy. ${ }^{5,6}$ In the third trimester, in physiological pregnancy, plasma bicarbonate concentration decreases, which reduces buffering capacity. ${ }^{8}$ Hepatic glycogen stores are depleted after prolonged fasting, leading to fatty acid metabolism and ketone body formation and acidosis. Women with comorbidities such as preeclampsia and gestational diabetes may be even more at risk for starvation. ${ }^{8}$ Preeclampsia can cause severe vomiting, which leads to progressive starvation due to less nutritional intake. ${ }^{6}$

Maternal metabolic acidosis may have severe consequences for both mother and the fetus. Maternal metabolic acidosis causes an increased maternal respiratory rate to decrease levels of $\mathrm{pCO}_{2}$ to return the $\mathrm{pH}$ level to a regular rate. ${ }^{10-12}$ The elevated respiratory rate is in turn associated with an increased risk for cardio-pulmonary arrests and ICU admission. ${ }^{13-15}$ Furthermore, the reduced blood flow caused by vasoconstriction due to decreased levels of $\mathrm{pCO}_{2}$ in the maternal circulation can cause fetal acidosis, which may result in impaired fetal neuronal function. ${ }^{4}$ The acidity within pregnancy is associated with intrauterine death due to transfer of ketones through the placenta, the maternal electrolyte imbalance and maternal volume depletion. ${ }^{6}$ Early recognition and treatment of a maternal acidosis is necessary to prevent these risks of morbidity and mortality.

\section{Conclusion}

Maternal acidosis is a medical emergency, in which both mother and child are at risk for significant morbidity and mortality. Acute starvation in the third trimester of pregnancy may lead to maternal metabolic ketoacidosis. Patients with comorbidity such as gestational diabetes and preeclampsia may be more at risk to develop starvation ketoacidosis. Due to the higher tendency of ketogenesis in pregnancy, clinicians should be aware of the risks of starvation. Pregnant women in respiratory distress after a period of starvation should be analysed for acidosis by arterial blood gas and urinalysis. When starvation has occurred, substituting nutrients, intravenous glucose and prevention of circulatory hypovolemia are recommended. Daily monitoring of respiratory rate, urine analysis for ketones and electrolytes are recommended to monitor a safe transition to a normal metabolic balance. Acute starvation should be identified rapidly to prevent maternal and fetal morbidity, and the right treatment with substitution should be given on time.

\section{Acknowledgments}

None.

\section{Author's contributions}

Each author has indicated that he or she has met the journal's requirements for authorship.

\section{Funding}

None.

\section{Conflicts of interest}

The authors declare that they have no conflicts of interest. 


\section{References}

1. Yeow $\mathrm{C}$, Wilson F, Walter E, et al. Perioperative diagnosis of euglycaemic ketoacidosis. J Intensive Care Soc. 2016;17(1):79-81.

2. McGuire LC, Cruickshank AM, Munro PT. Alcoholic ketoacidosis. Emerg Med J. 2006;23(6):417-420.

3. Burbos N, Shiner AM, Morris E. Severe metabolic acidosis as a consequence of acute starvation in pregnancy. Arch Gynecol Obstet. 2009;279(3):399-400

4. Cecere N, Hubinont C, Kabulu Kadingi A, et al. Extreme maternal metabolic acidosis leading to fetal distress and emergency caesarean section. Case Rep Obstet Gynecol. 2013;2013:847942.

5. Chausse JM, Paruk F, Motilall S, et al. Starvation ketoacidosis in pregnancy presenting as euglycaemic, high anion gap metabolic acidosis: A case report highlighting the significance of early recognition and prompt intervention. S Afr Med J. 2018;108(8):636-639.

6. Frise CJ, Mackillop L, Joash K, et al. Starvation ketoacidosis in pregnancy. Eur J Obstet Gynecol Reprod Biol. 2013;167(1):1-7.

7. Hui L, Shuying L. Acute starvation ketoacidosis in pregnancy with severe hypertriglyceridemia: A case report. Medicine (Baltimore). 2018;97(19):e0609.

8. Patel A, Felstead D, Doraiswami M, Stocks GM, Waheed U. Acute starvation in pregnancy: a cause of severe metabolic acidosis. Int $J$ Obstet Anesth. 2011;20(3):253-256.

9. Tarif N, Al Badr W. Euglycemic diabetic ketoacidosis in pregnancy. Saudi J Kidney Dis Transpl. 2007;18(4):590-593.

10. Narins RG, Emmett M. Simple and mixed acid-base disorders: a practical approach. Medicine (Baltimore). 1980;59(3):161-187.

11. Pierce NF, Fedson DS, Brigham KL, et al. The ventilatory response to acute base deficit in humans. Time course during development and correction of metabolic acidosis. Ann Intern Med. 1970;72(5):633-640.

12. Adrogué HJ, Madias NE. Secondary responses to altered acid-base status: the rules of engagement. J Am Soc Nephrol. 2010;21(6):920-923.

13. Fieselmann JF, Hendryx MS, Helms CM, et al. Respiratory rate predicts cardiopulmonary arrest for internal medicine inpatients. $J$ Gen Intern Med. 1993;8(7):354-360.

14. Subbe CP, Davies RG, Williams E, et al. Effect of introducing the Modified Early Warning score on clinical outcomes, cardio-pulmonary arrests and intensive care utilization in acute medical admissions. Anaesthesia. 2003;58(8):797-802.

15. Umar A, Ameh CA, Muriithi F, Mathai M. Early warning systems in obstetrics: A systematic literature review. PLoS One. 2019;14(5):e0217864. 